\title{
Research on residual bending capacities of used wood members based on the correlation between non-destructive testing results and the mechanical properties of wood"
}

\author{
Jin $\mathrm{ZHANG}^{\dagger 1}$, Qing-feng $\mathrm{XU}^{2}$, Yi-xiang $\mathrm{XU}^{3}$, Ming ZHANG ${ }^{1}$ \\ $\left({ }^{1}\right.$ Key Laboratory of Concrete and Prestressed Concrete Structures of Ministry of Education, Southeast University, Nanjing 210096, China) \\ ( 2 Shanghai Key Laboratory of New Technology Research on Engineering Structure, Shanghai Research \\ Institute of Building Sciences, Shanghai 200032, China) \\ $\left({ }^{3}\right.$ Department of Civil Engineering, Strathclyde University, Glasgow G12 8QQ, UK) \\ †E-mail: zhangjin0622@139.com
}

Received Sept. 15, 2014; Revision accepted Mar. 15, 2015; Crosschecked June 12, 2015

\begin{abstract}
To quantitatively assess the residual strength of wood members after rot and infestation using non-destructive testing (NDT), the multi-point Resistograph method was applied to test six used wood beams with initial imperfections. Each wood beam was then divided into a shorter segment for mechanical tests and a longer one for bending capacity tests. With the help of finite element analysis using ANSYS, bending capacity is predicted by taking account of the initial imperfections. Results show that there is a significant correlation between drill resistance values and strengths for small specimens. Therefore, the strengths of wood at other measurement points may be obtained through drill resistance values. The beams showed a near linear behaviour up to the maximum load with poor ductility performance in bending capacity tests. It can also be found that the effects of initial imperfections on failure modes and ultimate loads are significant. The lateral side of specimen BA1 has serious infestation and the bottom of BA2 has a long longitudinal crack, the ultimate bearing capacities of these specimens are respectively only $67.6 \%$ and $64.8 \%$ of BA3, which has fewer cracks. BB1 and BB3 have knots at the bottom and their ultimate bearing capacities are respectively $83.9 \%$ and $81.0 \%$ of BB2, which has fewer cracks as well. Furthermore, there is quite good agreement between test results and numerical prediction using strength values obtained by NDT results. Therefore, the bending capacity of used wood beams can be obtained using NDT, which can provide the basis for the protection and retrofitting of wood structures.
\end{abstract}

Key words: Used wood members, Non-destructive testing (NDT), Mechanical test, Residual bending capacity doi: $10.1631 /$ jzus.A1400276

\section{Introduction}

Wood is a natural material. It is subject to biological degradation phenomena due to environmental conditions. In addition, different structural abnormalities (e.g., carking, splitting) are often shown in

\footnotetext{
* Project supported by the National Natural Science Foundation of China (No. 51178115), the Priority Academic Program Development of Jiangsu Higher Education Institutions, and the Shanghai RisingStar Program (No. 11QH1402100), China

(DD) ORCID: Jin ZHANG, http://orcid.org/0000-0001-9906-3180

(C) Zhejiang University and Springer-Verlag Berlin Heidelberg 2015
}

wood members. For these reasons the condition of used wood members can be very variable. Thus, reliable tests of the physical and mechanical properties of wood and of the residual capacity of a member are essential in the evaluation of the structural capacity of existing timber structures and the specification of any reinforcing interventions that may be necessary (Bertolini et al., 1998; Tampone, 2001).

Non-destructive testing (NDT) evaluates the relevant characteristics of target objects through different physical, mechanical or chemical properties of their materials without damaging their internal and 
external properties and structures. NDT is especially suitable for the measurements of various defects. In general, original main structures should not be damaged in the process of maintenance and protection of wood buildings. Thus, NDT is needed for the evaluation of wood members.

In recent years, much research on damage detection in wood members by NDT has been carried out. Kraler et al. (2012) proposed that the nondestructive drilling resistance measurement method can be used to determine the relative density even after damage by fungi and insects has occurred. To assess the general quality of the timber, Lechner $e t$ al. (2014) applied stress-wave measurements in combination with resistance drilling and $\mathrm{X}$-ray measurements. Lee et al. (2014) assessed the residual performance of partially charred components of an old wooden structure by ultrasonic velocity testing and by measurement of drilling resistance. Tannert et al. (2014) summarized the test recommendations for selected semi-destructive testing techniques including resistance drilling, and provided users with sufficient information to understand the theoretical basis, typical equipment set up, and basic capabilities and limitations for such tests. Jasieńko et al. (2013) proposed that resistance drilling techniques are suitable for detecting internal defects, decay, and cracks, determining the location and dimensions of degraded areas, and assessing the mechanical properties of structural timber members. Schajer (2001) detected the size and location of knots with the help of a multi-probe density scanner. With the aid of infrared tomography, Kandemir-Yucel et al. (2007) detected the corruption level of an ancient wood building built in Japan in the 13 th century.

Nowadays, some international research efforts are aiming at directly correlating NDT information with physical and mechanical properties of wood (Feio et al., 2004; Kasal and Anthony, 2004). But in general, most studies concerning damaged status of wood members are qualitative. Wang et al. (2006) studied the relations between resistance value measured by Resistograph and air-dried density, bending strength and compressive strength parallel to the grain, respectively, and established regression models; validation test results showed that there were no significant differences between the measured values and those predicted by the regression model. Calderoni et al. $(2006$; 2010) carried out an experimental campaign of mechanical behavior tests and Resistograph NDTs on ancient chestnut elements for determining a correlation between NDT results and mechanical wood properties, previously obtained by means of destructive tests. Then, a numerical formulation between Resistograph tests carried out along the direction parallel to the grain and the longitudinal ultimate compressive stress was proposed.

This paper studies the quantitative relations between NDT results and tension/compression strengths of standard small specimens. Then, further studies concerning the residual bending capacity of wood members subjected to decay and insect damage are conducted. These provide quantitative bases for the protection and maintenance of wood buildings to avoid mindless dismantlement or replacement.

\section{NDT of wood beams}

\subsection{Specimens and measure points}

This research depends upon Resistograph NDTs on six service-beyond wood beams from Zhang et al. (2011). The wood beams are 80 years service-beyond and were retrieved from the Old Library in Southeast University, China when it was reinforced and reconstructed. Identification by the Laboratory of Wood, Shanghai Research Institute of Building Sciences, China showed that the wood beams are made of Douglas fir which belongs to Pinaceae. These beams have two kinds of cross-section, by number of BA1-BA3, BB1-BB3. The cross-sections of BA and $\mathrm{BB}$ are rectangular and regular along the length of the beams, whose dimensions are about $205 \mathrm{~mm} \times 300 \mathrm{~mm}$ and $170 \mathrm{~mm} \times 350 \mathrm{~mm}$, respectively. A small segment (with an average length of $1060 \mathrm{~mm}$ ) is used for the strength test for standard small specimens, and a large one (with an average length of $3000 \mathrm{~mm}$ ) is used for the bending test. The details of specimens are shown in Table 1.

For the large segment, measurement points were arranged every $0.3 \mathrm{~m}$ along the length. In the width direction, there are two measurement points because the cross-section of beam is wide. The number of measurement points is increased in sections of the 
pure bending segment and sections with serious corruption and infestation.

For the small segment, one measurement point was arranged in each zone to investigate the relation between strengths and NDT values.

Table 1 Details of specimens

\begin{tabular}{ccccc}
\hline Specimen & $\begin{array}{c}\text { Dimension } \\
(\mathrm{mm} \times \mathrm{mm} \times \mathrm{mm})\end{array}$ & $\begin{array}{c}\text { Specimen } \\
\text { No. }\end{array}$ & Type of test \\
\hline BA1 & BA1-S & $20 \times 20 \times 30$ & 9 & Compressive \\
& & $15 \times 4 \times 60$ & 6 & Tensile \\
& BA1-L & $206 \times 304 \times 3005$ & 1 & Bending \\
\hline BA2 & BA2-S & $20 \times 20 \times 30$ & 9 & Compressive \\
& & $15 \times 4 \times 60$ & 6 & Tensile \\
& BA2-L & $205 \times 301 \times 3004$ & 1 & Bending \\
\hline BA3 & BA3-S & $20 \times 20 \times 30$ & 9 & Compressive \\
& & $15 \times 4 \times 60$ & 6 & Tensile \\
& BA3-L & $205 \times 298 \times 3002$ & 1 & Bending \\
\hline BB1 & BB1-S & $20 \times 20 \times 30$ & 9 & Compressive \\
& & $15 \times 4 \times 60$ & 6 & Tensile \\
& BB1-L & $172 \times 350 \times 3000$ & 1 & Bending \\
\hline BB2 & BB2-S & $20 \times 20 \times 30$ & 9 & Compressive \\
& & $15 \times 4 \times 60$ & 6 & Tensile \\
& BB2-L & $169 \times 348 \times 3003$ & 1 & Bending \\
\hline BB3 & BB3-S & $20 \times 20 \times 30$ & 9 & Compressive \\
& & $15 \times 4 \times 60$ & 6 & Tensile \\
& BB3-L & $173 \times 353 \times 3003$ & 1 & Bending \\
\hline BAx-S & &
\end{tabular}

$\mathrm{BA} x$-S represents small specimen obtained from the small segment of BAx; BAx $x$ L represents the larger segment of BAx which is used for bending tests

\subsection{Test methods and results}

NDT of wood members was carried out by examining their appearance and by the Resistograph, which is a type of probe-based instrument.

First, appearance checks (visual evaluation and hammering) were conducted. Visual inspections are the basis of any analysis of traditional timber structures (Branco et al., 2010). The classifications of rot and infestation for measure points are respectively classified as follows according to Chinese regulation GB/T 13942.2-1992 (AQSIQ, 1992). Grade 1: no rot, no insects; Grade 2: primary decay, no insects; Grade 3: intermediate decay, no insects; Grade 4: primary decay, insects; Grade 5: intermediate decay, insects; Grade 6: intermediate decay, serious infestation.

The model of Resistograph device used in the experiment is IML F400-S series (IML Corporation, USA) which has a needle tip $3 \mathrm{~mm}$ in diameter and which can reach $380 \mathrm{~mm}$ in depth. The direction of the drilling path is perpendicular to the rings, from the measurement point toward the pith. The initial imperfections of the wood beams were detected by the Resistograph. With the help of an electric motor, a probe of the Resistograph was drilled into the wood member at a constant rate. The voltage of motor is constant, and the size of electric current responds to the drill resistance. So a relationship between the drill resistance value and the depth is obtained. Some drill resistance curves are shown in Fig. 1. The horizontal axis of the curve represents the depth of the probe piercing, and the vertical axis represents the drill resistance of the probe. Wood density changes and internal decay, cracks, insects, etc. will change with drill resistance values, which will be shown on the curve.
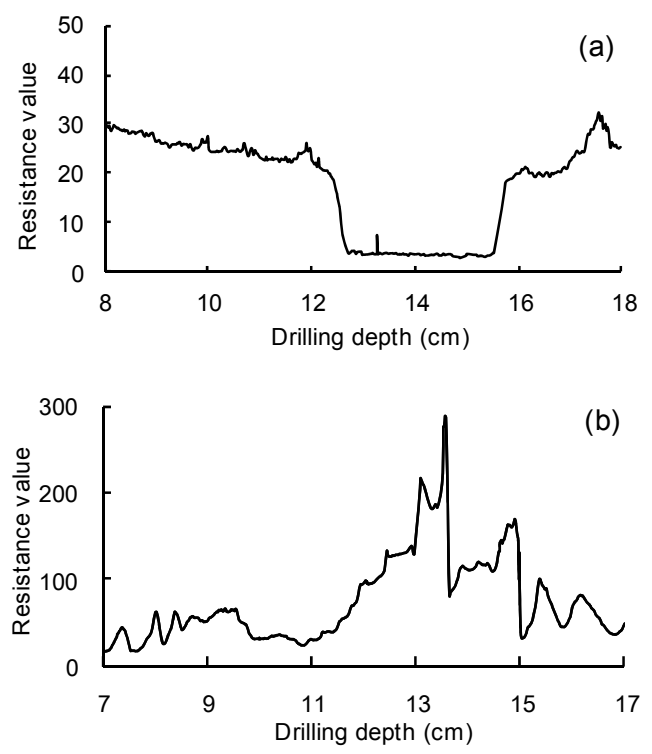

Fig. 1 Resistance-depth curves tested by the Resistograph (a) Serious insect parts of Douglas fir; (b) Knot positions of Douglas fir

\section{Test of small specimens}

\subsection{Relation between strengths and drill re-} sistance values of small specimens

There are nine specimens from one wood beam for the compression strength test parallel to the grain, and six specimens for tensile strength. All tests have been carried out according to GB/T 1932-2009 and GB/T 1938-2009 (AQSIQ, 2009a; 2009b).

Through the regression analysis of strengths of standard small specimens obtained from above 
material tests and drill resistance values from NDT, strengths of small specimens, $y$, against drill resistance values, $x$, were obtained (Fig. 2). Compression strengths and drill resistance values are interrelated, and the regression equation is $y=0.716 x+19.13$, where the correlation coefficient $R^{2}=0.693$. Tension strengths and drill resistance values are also correlated, and the regression equation is $y=0.876 x+14.41$, where the correlation coefficient $R^{2}=0.719$.
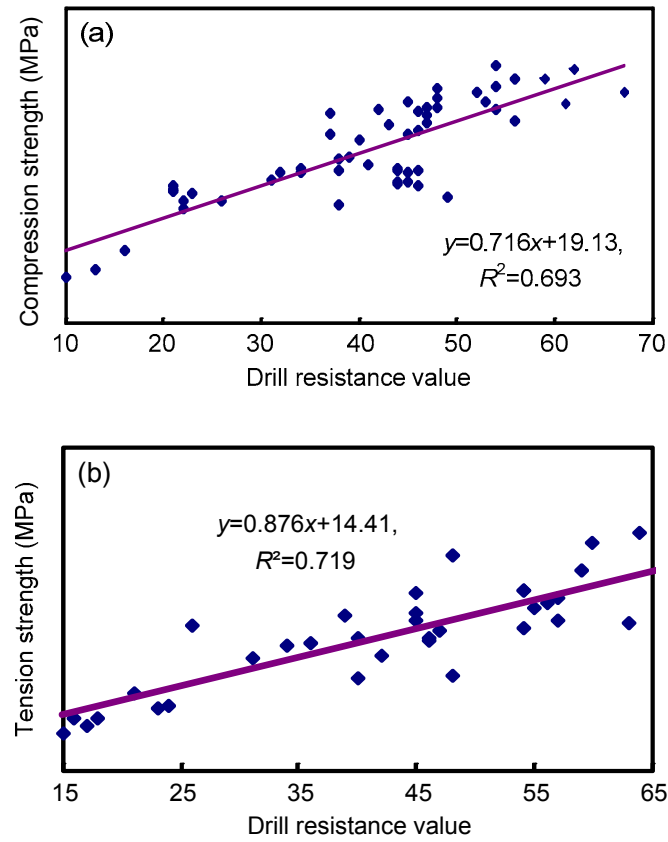

Fig. 2 Relation between timber strengths and drill resistance values

(a) Compression strengths; (b) Tension strengths

\subsection{Strength of the small specimen considering the influence of damage by insects}

For the large segment of wood beam used in the capacity test, substituting the drill resistance value into Fig. 2, we can obtain the strength of the small specimen considering the influence of damage by insects. As can be seen from Fig. 3, BA1 was divided into many zones and one measure point was set in each zone. It can be assumed that the strength of these measure points represents the strength of each zone. Other wood members are similar. Note that knots must be avoided when the beam is tested because the resistance value obtained from knots does not reflect the real strength of the zone.

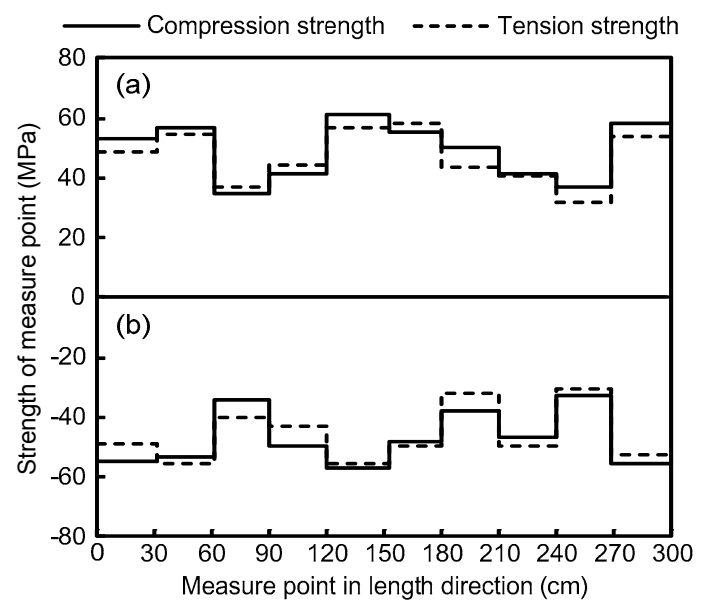

Fig. 3 Interval strength represented by each measure point in BA1

(a) Upper half of the beam; (b) Below half of the beam

\subsection{Elastic modulus}

Small specimens from BA1-BB3 were tested according to Chinese regulation GB/T 15777-1995 (AQSIQ, 1995). Compression elastic modulus $E$ parallel to the grain is shown in Table 2 .

Table 2 Elastic modulus parallel to the grain

\begin{tabular}{cc||cc}
\hline No. & $E(\mathrm{MPa})$ & No. & $E(\mathrm{MPa})$ \\
\hline BA1 & 5171 & BB1 & 5464 \\
BA2 & 6686 & BB2 & 5516 \\
BA3 & 5203 & BB3 & 6929 \\
\hline
\end{tabular}

\section{Residual capacity experiment of wood beams}

\subsection{Specimens and the loading system}

There is damage of varying degree in these six test beams because of old age. BA1 suffers from severe damage by insects about two-thirds along its side, and about $15 \%$ of the section is damaged; BA2 has a large crack at the bottom, which is about two-thirds of the beam length; the centre of BA3 has several micro cracks; there is a small crack in BB1 throughout its length and a knot at the bottom; there are a few small cracks in the central part of $\mathrm{BB} 2$; and there is a surface crack in BB3 and a large wood knot at the bottom.

In experiments, loads were exerted at one-third and two-thirds of the beam span. The loading process 
was controlled by load and divided into 10-15 grades, each grade equaled $15 \mathrm{kN}$ and lasted about 3-5 min.

\subsection{Failure modes and ultimate loads}

Taking specimen BA1 as an example, its failure process results are shown as follows. Throughout the test process, there was no crack in the end zone of BA1. When the load was increased to about $78 \%$ of the ultimate load, bottom corners of the loading location crazed. Cracks in the bottom face and the side face were about $50-80 \mathrm{~cm}$ long and a triangular piece was stripped out of the beam. Soon, with a loud noise, the specimen was destroyed. Although the proportion of the section damaged by insects was large, it still appeared to have a high bearing capacity. The plastic performance of the specimen is poor, without apparent cracks on its surface.

Failure modes and ultimate loads of other wood beams are shown in Table 3 and Fig. 4.

Table 3 Failure modes and ultimate loads

\begin{tabular}{|c|c|c|c|}
\hline No. & $\begin{array}{l}\text { Failure modes after } \\
\text { loading }\end{array}$ & $\begin{array}{l}\text { Ultimate } \\
\operatorname{load}(\mathrm{kN})\end{array}$ & $\begin{array}{c}\text { Ultimate } \\
\text { tensile strain } \\
(\mu \varepsilon)\end{array}$ \\
\hline$\overline{\mathrm{BA} 1}$ & $\begin{array}{l}\text { Wood fractures in tension } \\
\text { zone }\end{array}$ & 96 & 1782 \\
\hline BA2 & $\begin{array}{l}\text { Wood fractures along } \\
\text { original cracks in ten- } \\
\text { sion zone }\end{array}$ & 92 & 1921 \\
\hline BA3 & $\begin{array}{l}\text { Wood in tension zone } \\
\text { came into fractures; } \\
\text { small surface cracks }\end{array}$ & 142 & 1574 \\
\hline BB1 & $\begin{array}{l}\text { Wood damaged caused by } \\
\text { knots in tension zone, } \\
\text { cracks at the front end }\end{array}$ & 172 & 1693 \\
\hline BB2 & $\begin{array}{l}\text { Wood fracture in com- } \\
\text { pression zone, front end } \\
\text { damaged by shear } \\
\text { stress, wood fractures in } \\
\text { tension zone finally }\end{array}$ & 205 & 2214 \\
\hline BB3 & $\begin{array}{l}\text { Fractures in tension zone } \\
\text { around knots, cracks at } \\
\text { the front end }\end{array}$ & 166 & 1720 \\
\hline
\end{tabular}

These six beams all had initial imperfections of varying degree. These imperfections influenced failure modes and ultimate loads. There was severe insect damage in BA1 before loading and its ultimate load is lower. There were some big cracks in BA2 before loading and it was finally damaged along cracks with lower ultimate load than other beams without initial cracks. The ultimate loads of BA1 and BA2 are
$67.6 \%$ and $64.8 \%$ of that of BA3, respectively. There were big knots at the bottom of BB1 and BB3. They were both damaged by wood fractures around those knots. The ultimate loadings of BB1 and BB3 are $83.9 \%$ and $81.0 \%$ of that of $\mathrm{BB} 2$, respectively.

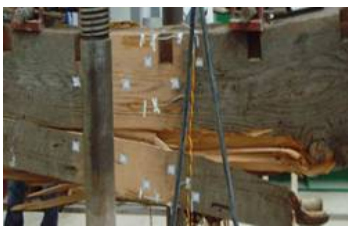

(a)

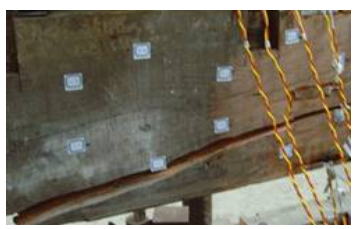

(c)

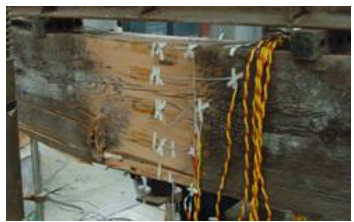

(e)

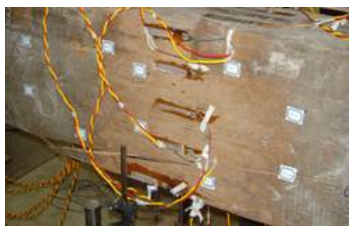

(b)

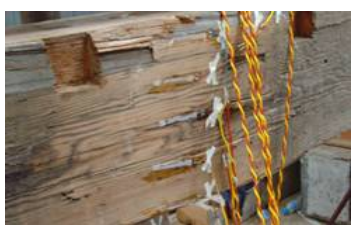

(d)

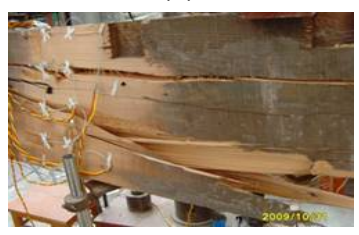

(f)
Fig. 4 Failure modes of timber specimens (a) BA1; (b) BA2; (c) BA3; (d) BB1; (e) BB2; (f) BB3

\subsection{Load-deflection curves}

Load-deflection curves of these two groups are shown in Fig. 5.

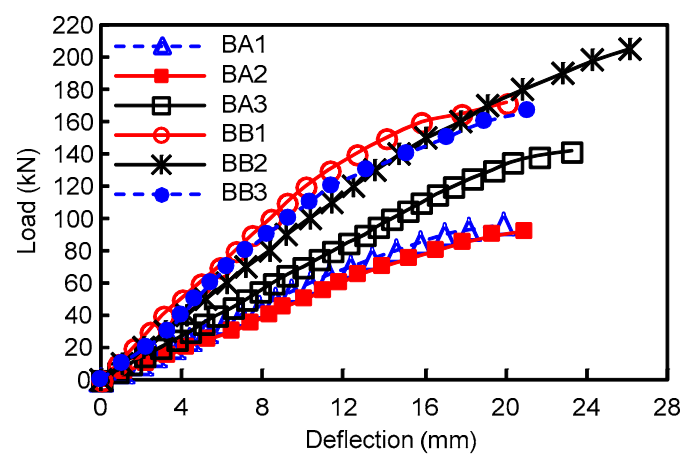

Fig. 5 Load-deflection curves of BA and BB

From Fig. 5, it is shown that the ultimate load and the rigidity of $\mathrm{BA} 3$ are larger than those of $\mathrm{BA} 1$ and BA2. Damage of BA1 by insects was much more serious, and there was a large crack at the bottom of BA2. So these two specimens both had obvious initial 
imperfections before loading. Load-deflection curves of these three specimens were almost linear from loading to failure. It means that the ductility of these three specimens is poor and failures are basically brittle.

Big knots in BB1 and BB3 at the bottom influenced their mechanical performance. Ultimate loads of them were both less than BB2. The stiffness of BB1 was the largest. At the initial stages of loading, the stiffness of BB3 was large but at the latter stages, the stiffness decreased gradually after wood fractures around knots. Load-deflection curves of these three specimens showed an almost linear increase from loading to failure. It means that the ductility of these three specimens is also poor with basically brittle failures.

\section{Finite element analysis}

\subsection{Basic assumptions and elastic coefficients}

Considering the test loading process was short, creep and relaxation behaviours were not taken into account in numerical simulations.

Basic assumptions in finite element calculations are as follows. Wood is an elastic-plastic material without creep and relaxation behaviours. Vertical, horizontal radial, and tangential directions of wood are orthotropic.

As an anisotropic material, wood has a total of nine independent elastic constants including the elastic modulus of L, R, T in three directions, Poisson's ratio, and the shear modulus of elasticity. In this study, the longitudinal elastic modulus $E_{\mathrm{L}}$ was obtained from the test while $E_{\mathrm{R}}$ and $E_{\mathrm{T}}$ were calculated according to the following relations (TDMEC, 2005): $E_{\mathrm{R}} / E_{\mathrm{L}}=0.10$, $E_{\mathrm{T}} / E_{\mathrm{L}}=0.05$. Values of the Poisson's ratio were $\mu_{\mathrm{RT}}=$ $0.43, \mu_{\mathrm{TL}}=0.02$, and $\mu_{\mathrm{RL}}=0.08$, and those of the shear modulus were: $G_{\mathrm{RT}}=100 \mathrm{MPa}, G_{\mathrm{TL}}=900 \mathrm{MPa}$, and $G_{\mathrm{RL}}=1100 \mathrm{MPa}$.

\subsection{Constitutive relation}

The compression modulus parallel to the grain is much larger than that vertical to the grain, which is shown in Fig. 6 (Wang, 2010).

Fig. 7 is the stress-strain curve parallel to the grain. In Fig. 7, "the test curve" refers to the stressstrain relation curve of a small specimen parallel to the grain, which was obtained in Section 3.

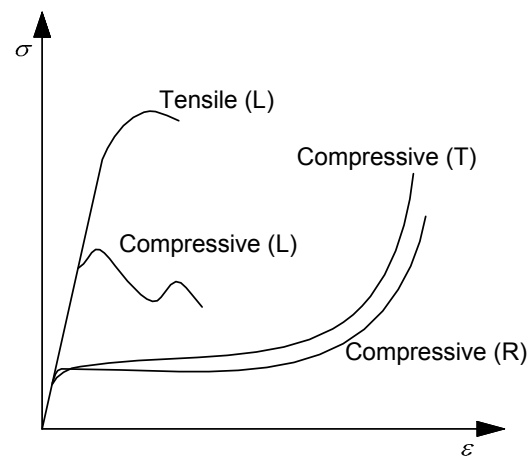

Fig. 6 Typical wood constitutive relation (Wang, 2010) $\varepsilon$ represents the strain of wood; $\sigma$ represents the stress of wood; L, R, and $\mathrm{T}$ represent the longitudinal, radial, and tangential directions of wood, respectively

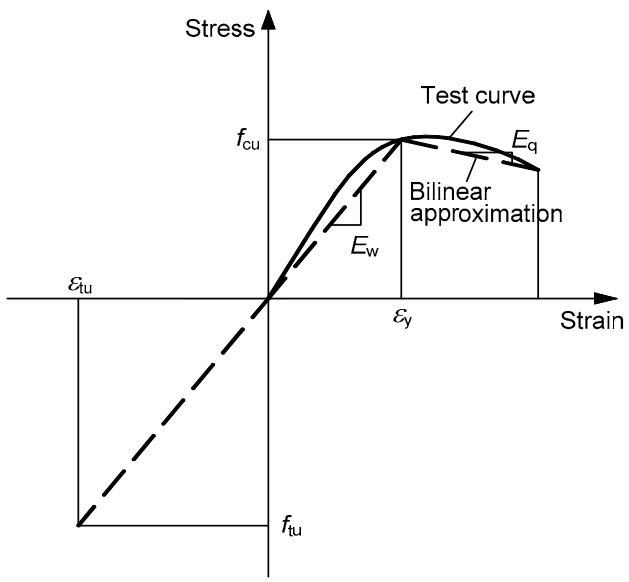

Fig. 7 Stress-strain curves of wood parallel to grain $\varepsilon_{\mathrm{y}}$ : yield strain of wood in compression; $\varepsilon_{\mathrm{tu}}$ : ultimate strain of wood in tension; $f_{\mathrm{cu}}$ and $f_{\mathrm{tu}}$ : ultimate stresses in compression and tension; $E_{\mathrm{w}}$ and $E_{\mathrm{q}}$ : elasticity and tangent moduli

The constitutive relation of the wood parallel to the grain approximately meets the following several aspects (Song et al., 2010).

1. The tension modulus and compression modulus of elasticity are almost identical.

2. When wood bears tension parallel to the grain, there is no obvious plastic deformation stage before damage. The stress-strain curve is almost linear and the failure mode is brittle. When wood bears compression parallel to the grain, there is an obvious plastic deformation stage before damage because of the buckling instability of wood fibers.

\subsection{Finite element model}

This study adopts Solid45 element of ANSYS software to simulate wood characteristics with Hill 
yield criteria, which takes into account elastic parameters and the anisotropic yield strength of wood to analyze its elastic-plastic behaviour. The model is divided into a grid of sixths along its width, twelfths along its height, and sixtieths along its length. The mesh size is approximately $50 \mathrm{~mm} \times 33 \mathrm{~mm} \times 25 \mathrm{~mm}$, and the beam is simply supported (Fig. 8). The Newton Raphson method was used in the process of analysis.

The following aspects have been taken into account when setting the finite element model (FEM). (1) According to the results of NDT, the materials strengths of different zones of the wood beam are different (Fig. 3). In the calculation model in Fig. 8, different colors represent different zones and the material strength obtained from NDT for each zone has been adopted separately. (2) Cushion blocks have been set in the model to prevent local stress concentration. Common nodes have been adopted at junctions of the wood beam and cushion blocks.

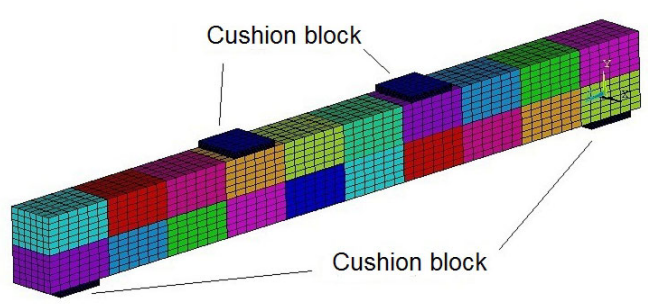

Fig. 8 Finite element model of the wood beam

\subsection{Simulations of initial imperfections}

BA1 had suffered from severe damage by insects such that a partial cross-section became invalid. Therefore, this part was not considered and the cross-section of the BA1 after meshing is shown in Fig. 9a.

There were initial cracks at the bottom of BA2. Thus, the finite element simulation did not consider wood around those cracks (Fig. 9b).

There were initial knots at the bottom of BB1 and BB3. The directions of wood grains change around knots (TDMEC, 2005). Therefore, they were redefined while defining material properties, namely $X$ axis of the global coordinate system stands for the wood longitudinal direction (L), $Y$ axis for radial direction (R), and $Z$ axis tangential direction (T). Simulations of knots are shown in Fig. 9c.
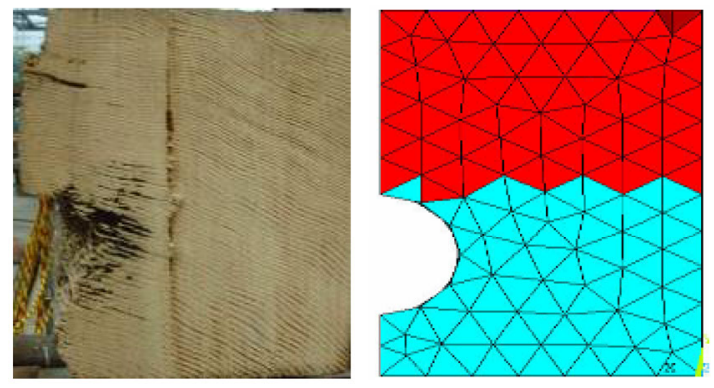

(a)
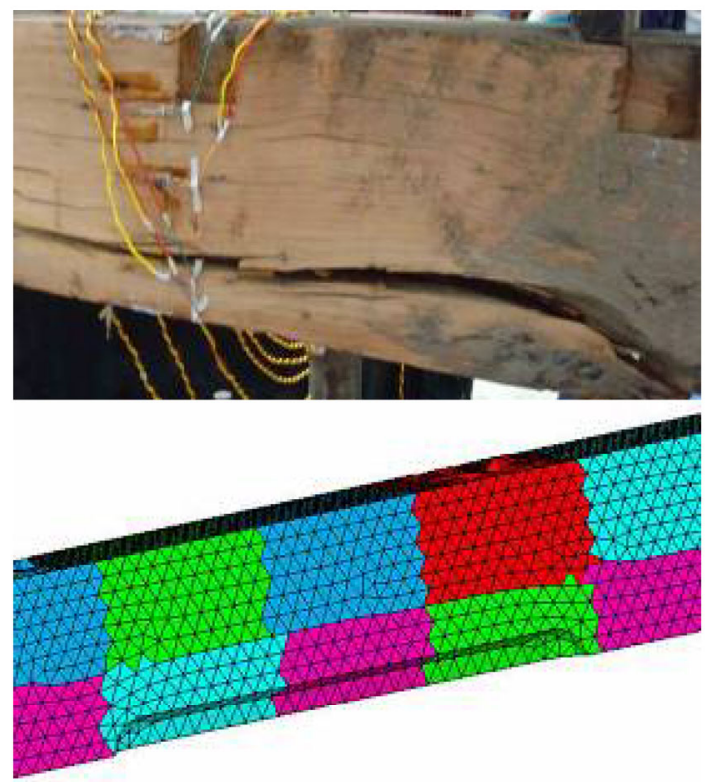

(b)
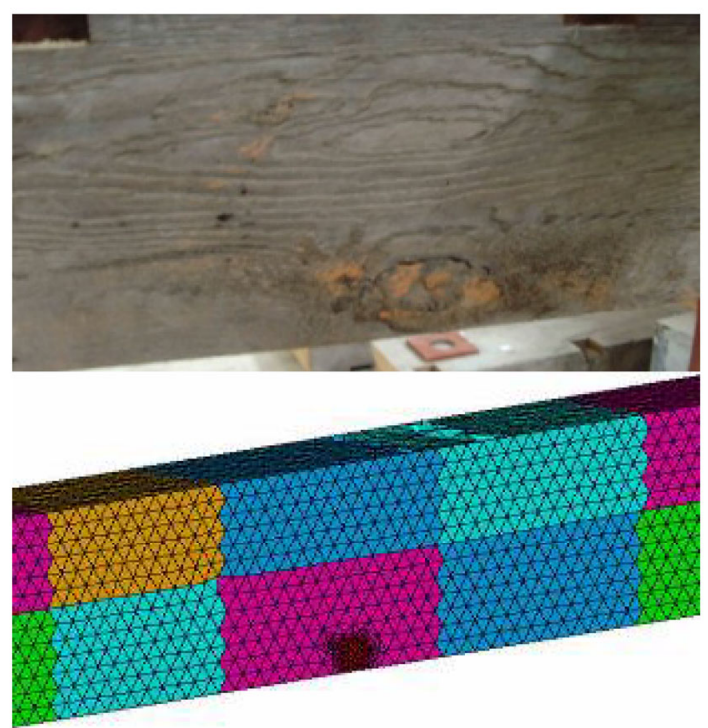

(c)

Fig. 9 FEM simulations of initial imperfections (a) Section damaged by insects; (b) Crack; (c) Knot 


\section{Comparison between calculation results and test results}

\subsection{Comparison of failure modes}

Taking specimen BA1 as an example, FEM calculation results of the strains are shown in Fig. 10. Strains of each specimen under the ultimate load parallel to the grain are shown in Table 4 .
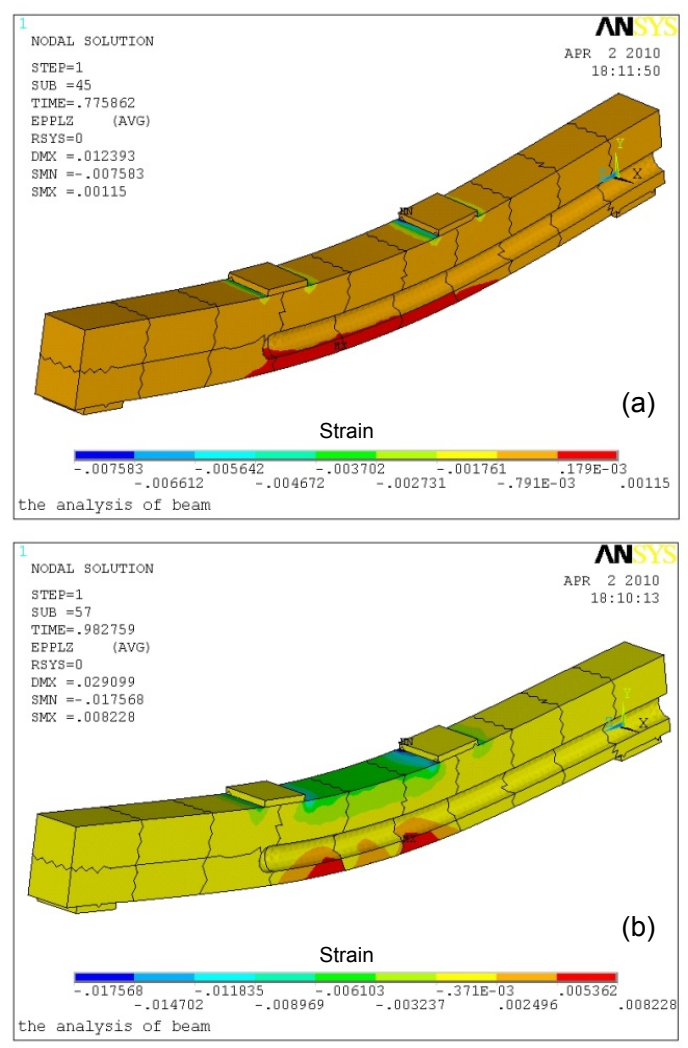

Fig. 10 Calculation of plastic strains of BA1

(a) Under the yield load; (b) Under the ultimate load

Table 4 Calculated strains of each specimen

\begin{tabular}{cccccc}
\hline & \multirow{2}{*}{$\begin{array}{c}\text { Ultimate } \\
\text { No. }\end{array}$} & \multicolumn{4}{c}{ Strain $(\mu \varepsilon)$} \\
& $(\mathrm{kN})$ & $\begin{array}{c}\text { centre of compression } \\
\text { area at mid-span }\end{array}$ & \multicolumn{2}{c}{$\begin{array}{c}\text { Centre of tension } \\
\text { area at mid-span }\end{array}$} \\
& & $\varepsilon_{\mathrm{e}}$ & $\varepsilon_{\mathrm{p}}$ & $\varepsilon_{\mathrm{e}}$ & $\varepsilon_{\mathrm{p}}$ \\
\hline BA1 & 114 & -1595 & -2614 & 1588 & 4332 \\
BA2 & 112 & -2032 & -1805 & 1987 & 3084 \\
BA3 & 155 & -2125 & -2309 & 2094 & 3778 \\
BB1 & 205 & -1157 & -3972 & 1132 & 5341 \\
BB2 & 227 & -1559 & -3476 & 1589 & 5177 \\
BB3 & 195 & -1192 & -2774 & 1192 & 5604 \\
\hline
\end{tabular}

Note: $\varepsilon_{\mathrm{e}}$ and $\varepsilon_{\mathrm{p}}$ represent the elastic strain and plastic strain, respectively
Through comparisons of failure modes and FEM results of strains under ultimate loads, it is found that as follows:

1. For BA1, BB2, and BA3, calculated results of tension strain in the tension zone at the bottom of the beam are the largest and wood fibers at this position came into fracture in the test.

2. Wood fibers around initial cracks of BA2 came into failure in the test. Calculated results also show that tension strains at that location are the largest.

3. It can be concluded that the failures of BB1 and $\mathrm{BB} 3$ are all due to initial cracks. It is also obvious from the calculated results that strains at this position are much larger than those at other positions.

\subsection{Comparisons of ultimate loads}

Comparisons of ultimate loads between test and calculation are shown in Fig. 11. Digits in Fig. 11 represent the ratio of the calculated value to the test value.

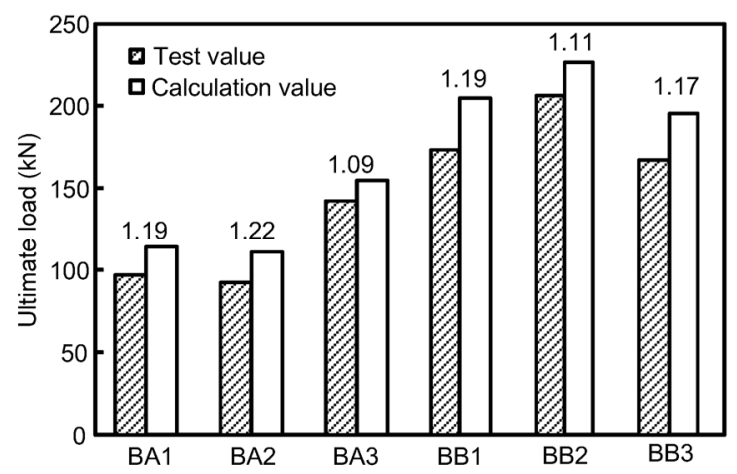

Fig. 11 Comparisons of ultimate loads between test and calculation

Fig. 11 shows that the calculated values of ultimate loads of all specimens are all larger than those from the tests but the values differ within less than $22 \%$. For some reasons not yet known, calculated values are always slightly greater. There are several factors may lead to this variance between experimental results and numerical simulation: the scale effect, the imperfection of constitutive model, and the local nature of NDT. This question requires further study.

There were severe damages by insects in BA1 and large initial cracks at the bottom of BA2. Although these initial imperfections have been taken into 
account in FEA, the ratios of calculated values to test values are still large, at 1.19 for BA1 and 1.22 for BA2.

There were big knots at the bottom of both BB3 and BB1. Although the influence of wood knots has been dealt with in FEA, the ratios of calculated values to the test values are still large, at 1.19 for BB1 and 1.17 for BB3.

\section{Conclusions}

1. Compression strengths and drill resistance values are interrelated and the regression equation is $y=0.716 x+19.13$, where the correlation coefficient $R^{2}=0.693$. Tension strengths and drill resistance values are also correlated and the regression equation is $y=0.876 x+14.41$, where the correlation coefficient $R^{2}=0.719$.

2. Initial imperfections have significant effects on the failure mode and the ultimate load. BA1 has serious cracks on the lateral side; BA2 has long longitudinal cracks at the bottom; BA3 has less cracks. The ultimate loads of BA1 and BA2 are $67.6 \%$ and $64.8 \%$ of that of BA3, respectively. Both BB1 and $\mathrm{BB} 3$ have a small amount of cracks and knots at the bottom. BB2 has a small amount of cracks only. The ultimate loadings of BB1 and BB3 are $83.9 \%$ and $81.0 \%$ of that of $\mathrm{BB} 2$, respectively.

3. Influences of initial imperfections (damage by insects, cracks, and knots) of specimens have been taken into account in FEA. However, ultimate loads of calculation values are all larger than those of test values but with less than $22 \%$ errors. The discrepancy in ratios of calculated values to test values is therefore not large. With further corrections it can satisfy the requirements of applications of timber engineering. The proposed method can be used as a reference for practical engineering.

\section{References}

AQSIQ (General Administration of Quality Supervision, Inspection and Quarantine of the People's Republic of China), 1992. Method for Field Test of Natural Durability of Wood, GB/T 13942.2-1992. Standards Press of China, Beijing, China (in Chinese).

AQSIQ (General Administration of Quality Supervision, Inspection and Quarantine of the People's Republic of China), 1995. Method for Determination of the Modulus of Elasticity in Compressive Parallel to Grain of Wood,
GB/T 15777-1995. Standards Press of China, Beijing, China (in Chinese).

AQSIQ (General Administration of Quality Supervision, Inspection and Quarantine of the People's Republic of China), 2009a. Method of Testing in Compressive Strength Parallel to Grain of Wood, GB/T 1932-2009. Standards Press of China, Beijing, China (in Chinese).

AQSIQ (General Administration of Quality Supervision, Inspection and Quarantine of the People's Republic of China), 2009b. Method of Testing in Tensile Strength Parallel to Grain of Wood, GB/T 1938-2009. Standards Press of China, Beijing, China (in Chinese).

Bertolini, C., Brunetti, M., Cavallaro, P., et al., 1998. A non-destructive diagnostic method on ancient timber structures: some practical application examples. Proceedings of 5th World Conference on Timber Engineering, Montreux, Switzerland, p.456-465.

Branco, J.M., Piazza, M., Cruz, P.J.S., 2010. Structural analysis of two King-post timber trusses: non-destructive evaluation and load-carrying tests. Construction and Building Materials, 24(3):371-383. [doi:10.1016/j.conbuildmat. 2009.08.025]

Calderoni, C., de Matteis, G., Giubileo, C., et al., 2006. Flexural and shear behaviour of ancient wooden beams: experimental and theoretical evaluation. Engineering Structures, 28(5):729-744. [doi:10.1016/j.engstruct.2005. 09.027]

Calderoni, C., de Matteis, G., Giubileo, C., et al., 2010. Experimental correlations between destructive and nondestructive tests on ancient timber elements. Engineering Structures, 32(2):442-448. [doi:10.1016/j.engstruct.2009. $10.006]$

Feio, A.O., Lourenco, P.B., Machado, J.S., 2004. Compressive behaviour and NDT correlations for chestnut wood. Proceedings of the 4th International Seminar Structural Analysis of Historical Constructions, Padova, Italy.

Jasieńko, J., Nowak, T., Hamrol, K., 2013. Selected methods of diagnosis of historic timber structures - principles and possibilities of assessment. Advanced Materials Research, 778:225-232. [doi:10.4028/www.scientific.net/AMR.778. 225]

Kandemir-Yucel, A., Tavukcuoglu, A., Caner-Saltik, E.N., 2007. In situ assessment of structural timber elements of a historic building by infrared thermography and ultrasonic velocity. Infrared Physics \& Technology, 49(3):243-248. [doi:10.1016/j.infrared.2006.06.012]

Kasal, B., Anthony, R.W., 2004. Advances in in situ evaluation of timber structures. Progress in Structural Engineering and Materials, 6(2):94-103. [doi:10.1002/pse.170]

Kraler, A., Beikircher, W., Zingerle, P., 2012. Suitability of drill resistance measurements for dendrochronological determination. World Conference on Timber Engineering, Auckland, New Zealand.

Lechner, T., Nowak, T., Kliger, R., 2014. In situ assessment of the timber floor structure of the Skansen Lejonet fortification, Sweden. Construction and Building Materials, 
58:85-93. [doi:10.1016/j.conbuildmat.2013.12.080]

Lee, H.M., Hwang, W.J., Lee, D.H., et al., 2014. Evaluation of the residual performance of partially charred components of old wooden structure I-use of ultrasonic velocity and testing of the drilling resistance. Journal of the Korean Wood Science and Technology, 42(2):193-206. [doi:10. 5658/WOOD.2014.42.2.193]

Schajer, G.S., 2001. Lumber strength grading using X-ray scanning. Forest Products Journal, 51(1):43-50.

Song, X.B., Lam, F., Huang, H., et al., 2010. Stability capacity of metal plate connected wood truss assemblies. Journal of Structural Engineering, 136(6):723-730. [doi:10.1061/ (ASCE)ST.1943-541X.0000163]

Tampone, G., 2001. Acquaintance of the ancient timber structures. In: Lourenço, P.B., Roca, P. (Eds.), Historical Constructions, Guimarães, p.117-144.

Tannert, T., Anthony, R., Kasal, B., et al., 2014. In situ assessment of structural timber using semi-destructive techniques. Materials and Structures, 47(5):767-785. [doi:10.1617/s11527-013-0094-5]

TDMEC (Timberwork Design Manual Editing Committee), 2005. Timberwork Design Manual, 3rd Edition. China Architecture \& Building Press, Beijing, China, p.16-22 (in Chinese).

Wang, X.H., Huang, R.F., Zheng, H.K., et al., 2006. Quantitative analysis on measure results by Resistograph for wood decay of ancient architecture. Chinese Forestry Science and Technology, 5(4):16-22 (in Chinese).

Wang, Y.C., 2010. Research on Testing Competence Evaluation and FRP Strengthened Experiments of Servicebeyond Wood Members. MS Thesis, Southeast University, Nanjing, China (in Chinese).
Zhang, J., Wang, Y.C., Xu, Q.F., et al., 2011. Residual strength of service-beyond wood members of Douglas fir and cedarwood using non-destructive testing. Journal of Central South University (Science and Technology), 42(12):38643870 (in Chinese).

\section{中文概要}

题 目: 基于无损检测与木材力学性能相关性的既有木构 件剩余抗弯承载力研究

目 的: 利用无损检测的方法, 定量评估经腐朽和虫蛙后 的既有木构件的剩余抗弯承载力。

方 法: 1. 通过对木材小试件进行阻抗仪检测试验和材性 试验, 建立木材阻力值与抗压/抗拉强度之间的线 性回归方程; 2. 对大段木梁试件进行阻抗仪检测 试验, 基于木材阻力值与抗压/抗拉强度之间的关 系, 计算得到大段木梁各部分的强度值; 3. 在 Abaqus 中对既有木梁的初始缺陷进行模拟并将 木梁的计算强度值赋予木梁的各个部分, 综合分 析木梁的剩余抗弯承载力。

结 论: 1. 木材小试件的阻力值与抗压/抗拉强度值之间呈 现出显著的相关性, 各测点处的木材强度值可通 过阻力值计算得到; 2. 虫蛙、木节和裂缝等初始 缺陷对试件的破坏形式和极限荷载影响显著; 3. 非线性仿真分析所得的结果与试验结果基本 吻合。

关键词: 既有木构件; 无损检测; 力学试验; 剩余抗弯承 载力 